\title{
A Proposal and Verification of the Lunar Overnight Method by Promoting the Heat Exchange with Regolith
}

\author{
Shogo Okishio ${ }^{1}$ and Hosei Nagano. ${ }^{2}$ \\ Nagoya University, Nagoya, Aichi, 464-0814, Japan \\ and \\ Hiroyuki Ogawa ${ }^{3}$ \\ Japan Aerospace Exploration Agency, Sagamihara, Kanagawa, 229-8510, Japan
}

\begin{abstract}
This paper presents a study on the optimization of a lunar lander for surviving extremely cold lunar nights by using completely passive thermal control. The effects of parameters such as shape, thermal conductance, and effective emissivity on temperature swings of the lunar lander were numerically analyzed. On the basis of the results, some candidate models were formed and the temperature swings of each model were compared. Then, from the viewpoint of feasibility, a particular model was selected. The model was scaled and experimental comparisons were performed. These comparisons proved the efficiency of the proposed model, both numerically and experimentally.
\end{abstract}

\section{Nomenclature}

$\begin{array}{ll}\rho & =\text { density } \\ C_{p} & =\text { specific heat }\end{array}$

$\lambda=$ thermal conductivity

$\alpha=$ solar absorptivity

$\epsilon \quad=$ emissivity

$h \quad=$ thermal conductance

$f \quad=$ heat frequency

$L_{t} \quad=$ thermal diffusivity length

$d \quad=$ constant temperature depth

RHU Radioisotope heater unit

RHG Radioisotope heat generator

\section{Acronyms}

\section{Introduction}

$\mathrm{R}$

ECENTLY, efforts to explore the moon have been increasing worldwide. However, long lunar durations present a challenge for thermal control. The environment of the lunar surface is different from that of the earth: it is a high-vacuum environment, where a single lunar day is 29.53 Earth days. ${ }^{1}$ These features cause temperature swings on the lunar surface of approximately $-190^{\circ} \mathrm{C}$ to $+100^{\circ} \mathrm{C}$. The thermal control of spacecrafts in this environment is very important because most of the equipment on spacecrafts has to be kept within a temperature range of $-40^{\circ} \mathrm{C}$ to $+50^{\circ} \mathrm{C}^{2}$ Currently nuclear power is used for accomplishing this task. Radioisotope heating units (RHUs) and radioisotope heat generators (RHGs) were used in early lunar exploration programs conducted by the Soviet Union and the United States in the 1960s and 70s. However, the use of radioisotopes should be avoided because they are pollutants. Radioisotopes also require careful handling and installation procedures to protect personnel. Solutions for surviving on the lunar surface without relying on nuclear power have been researched worldwide. One such solution is thermal wadis. ${ }^{3}$ Thermal wadis are engineered sources of solar energy that are

\footnotetext{
${ }^{1}$ Graduate student, Department of Aerospace Engineering, Furo-cho, Chikusa-ku,

${ }^{2}$ Associate professor, Department of Aerospace Engineering, Furo-cho, Chikusa-ku, AIAA Member.

${ }^{3}$ Associate professor, Institute of Space and Astronautical Science, Sagamihara, 3-1-1, Yoshinodai, AIAA Menber.
} 
stored using modified lunar regolith as a thermal storage mass during the lunar night. However, this has not yet become a universal solution because the instruments are heavy and complicated. Therefore, new thermal controls for lunar exploration still require additional research. Our research group researched and proposed a new thermal control method for the lunar surface using regolith properties. ${ }^{4}$ The basic idea of this method is to interact with the constant-temperature layer of regolith, whose existence was confirmed by Apollo measurements. To prove the effectiveness of the proposed method, some experiments and thermal analyses were conducted under several assumptions. The work revealed the feasibility of a long-duration lunar lander that uses in situ lunar resources to make a completely passive thermal control system without using electrical power. In this paper, the optimization of previous models for achieving this goal is discussed, and the feasibility of the proposed model is verified numerically and experimentally.

\section{Thermal Models}

First, the thermal analysis models of the lunar surface and lander were formed. Table 1 shows the dependencies of regolith properties considered in this study. The density of regolith depends on depth, its specific heat depends on temperature, and its thermal conductivity depends on depth and temperature. ${ }^{4}$ The regolith density ${ }^{5}$, thermal capacitance $^{6}$, and thermal conductivity used in the analysis are shown in Figure 1 and Figure 2. Using these properties, the constant-temperature layer of the lunar regolith appears at a depth of $0.3 \mathrm{~m}$ below the surface. This is caused by the low thermal conductivity of regolith, although large temperature swings exist simultaneously on the surface. This work was mainly conducted in Ref. 4 . Solar absorptance and emissivity numbers are obtained from the work of Ref. 2. Table 2 shows the orbit information of the numerical model, which represents the equator. The maximum heat flux for the sunlight reflected from the earth is $0.111 \mathrm{~W} / \mathrm{m}^{2}$. Therefore, the albedo and IR planet that shine from Earth are both extremely small compared to the solar power and can be neglected. ${ }^{2}$ The lunar internal heat flow was measured between 0.016 and $0.021 \mathrm{~W} / \mathrm{m}^{2}$, which is set as the imposed heat flux of $0.019 \mathrm{~W} / \mathrm{m}^{2}$ in this study. ${ }^{7}$

Figure 3 shows a schematic of the lunar surface model. Its size is $20 \times 20 \times 1 \mathrm{~m}^{3}$ with about 51,000 nodes. The lunar surface temperature in this model compares well with those of other works.

Table 1. Dependencies of regolith properties considered in this study ${ }^{2,4}$

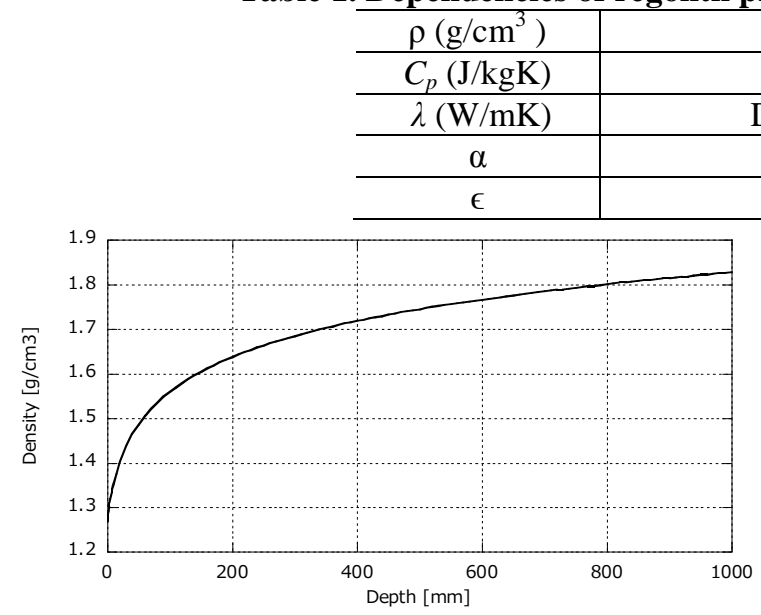

(a)
Depth

Temperature Depth, temperature

0.9

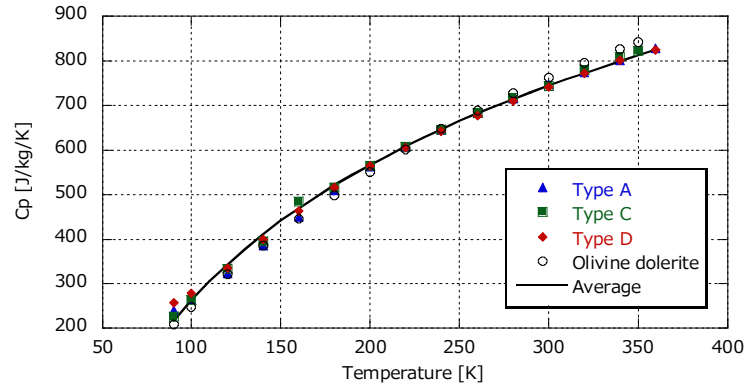

(b)

Figure 1. (a) Regolith density, (b) Regolith thermal capacitance.

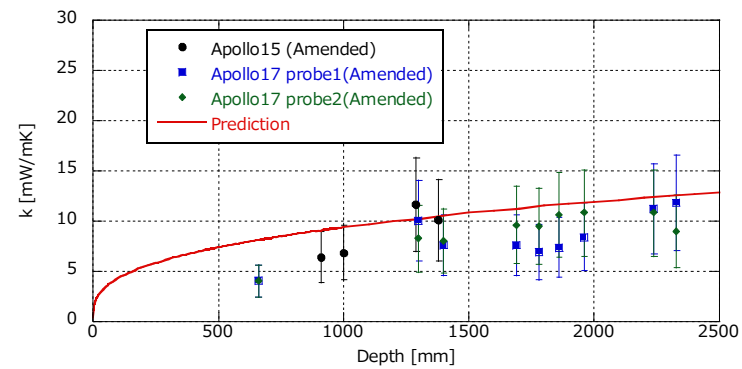

(a)

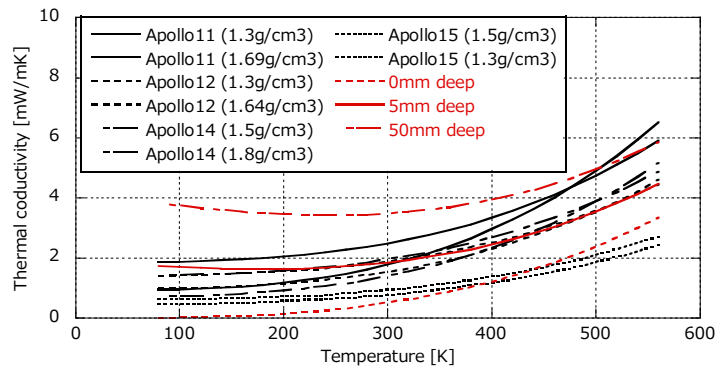

(b)

Figure 2. (a) Regolith thermal conductivity vs $\operatorname{depth}^{8}$ (b) Regolith thermal conductivity vs temperature. ${ }^{9-11}$ 
Table 2. Lunar orbit conditions ${ }^{1}$

\begin{tabular}{c|c}
\hline Orbit Altitude & $397,000 \mathrm{~km}$ \\
\hline Orbit Period & $2.545 \times 10^{6} \mathrm{sec}(29.53$ days $)$ \\
\hline Solar Power & $1354 \mathrm{~W} / \mathrm{m}^{2}$ \\
\hline Imposed heat flux & $0.019 \mathrm{~W} / \mathrm{m}^{2}$ \\
\hline Albedo (Earth) & 0 \\
\hline IR Planet shine (Earth) & 0 \\
\hline Albedo (Moon) & 0.13 \\
\hline$\beta$ Angle & $1^{\circ} 32^{\prime}$
\end{tabular}

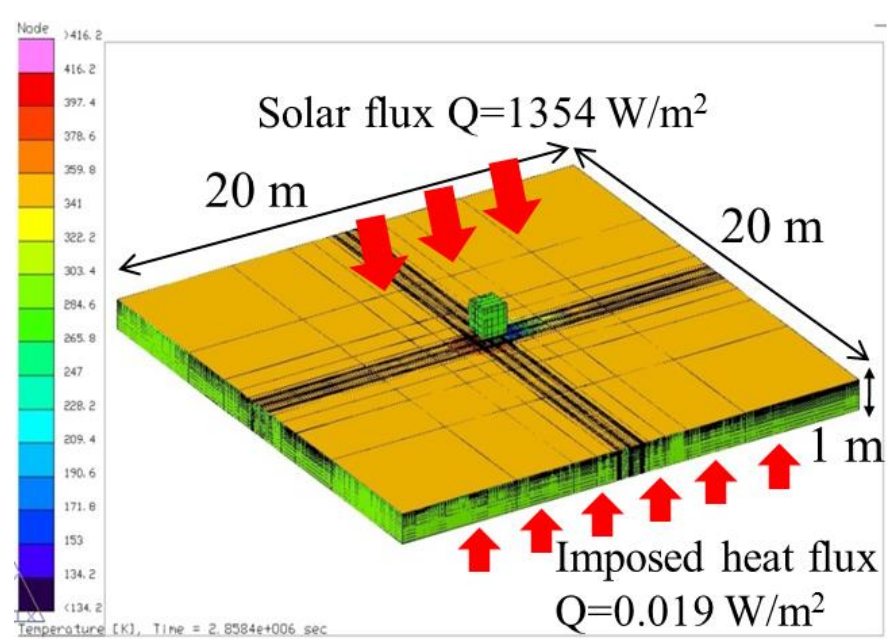

Figure 3. Schematic of lunar surface model.

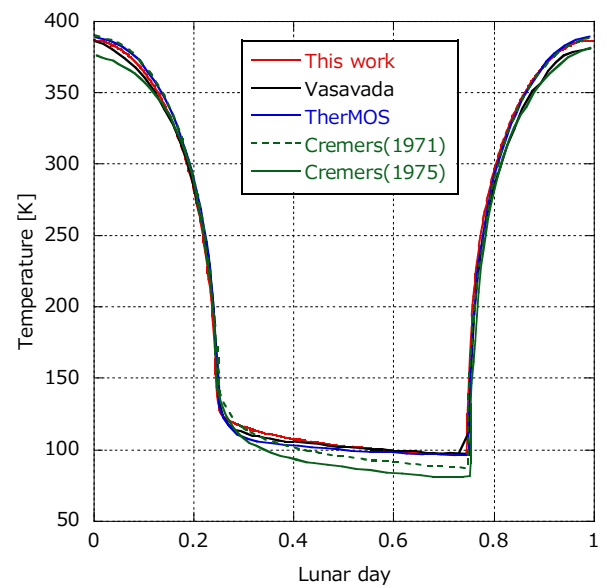

Figure 4. Lunar model surface temperature compared with other works. ${ }^{12-14}$

\section{A. Prime model proposal}

A $1 \mathrm{~m}^{3}$ model lander is placed at the center of the lunar surface model. It has 1-cm-thick aluminum honeycomb panels, which are covered with multilayer insulation (MLI). (Table 3). There is no internal thermal capacitance or internal heat generation from within this model. Although this is the worst case, it clarifies the relation between the regolith and lander, which enables us to see the significant effects of lunar regolith. Suspending this model $30 \mathrm{~cm}$ above the lunar surface is a non-active thermal control model. Four other types of model landers are constructed and compared. 
Table 3. Model lander factor

\begin{tabular}{c|c}
\hline Size & $1 \mathrm{~m} \times 1 \mathrm{~m} \times 1 \mathrm{~m}$ \\
\hline Material & Alminium honeycomb \\
\hline Insulation & Multilayer insulation (10 layers) \\
\hline Inside + Outside of bottom surface & Black paint \\
\hline Internal heating & $0 \mathrm{~W}$ \\
\hline
\end{tabular}

\section{a) Skirt model}

The skirt model is based on JAXA's thermal control proposal, which is shown in Figure 5a). ${ }^{15}$ The skirt is also aluminum honeycomb covered with 10 layers of MLI positioned at $45^{\circ}$ from the regolith surface. The purpose of this model is to suppress the temperature fluctuations of the regolith beneath the lander. In the analysis, it is assumed that there is no thermal resistance between the lander and skirt.

\section{b) Ground touch model}

The bottom surface of the lander touches the regolith surface. The clearance between the lander and regolith affects the lander temperature fluctuations. It is suggested that fluctuations decrease with clearance. ${ }^{4}$ By setting the lander as in Figure 5b), which represents zero clearance, radiation from the lander bottom is suppressed.

\section{c) Ground touch + Leg model}

This model is shown in Figure 5c). This is a model based on the Ground touch model but with four aluminum alloy $\left(\lambda=167 \mathrm{~W} / \mathrm{mK}, \rho=2700 \mathrm{~kg} / \mathrm{m}^{3}\right)$ legs installed underneath the lander. The legs are $\varnothing 50 \mathrm{~mm} \times 300 \mathrm{~mm}$ long. The thermal conductance between the lander and the legs is assumed to be fully coupled. The aim of the model is to interact with the constant-temperature layer of the regolith by inserting legs into the regolith.

\section{d) Ground touch + Sting model}

This model is developed model using the Ground touch + leg model. It was believed that if aluminum alloy had enough contact surface for heat exchange and enough strength to bear insertion, it could be thinner than legs. Thus, the sting model in Figure 5d) was constructed. The 25 stings are $\varnothing 5 \mathrm{~mm} \times 300 \mathrm{~mm}$ aluminum alloy rods. Thermal conductance between the lander and stings is also assumed to be fully coupled.

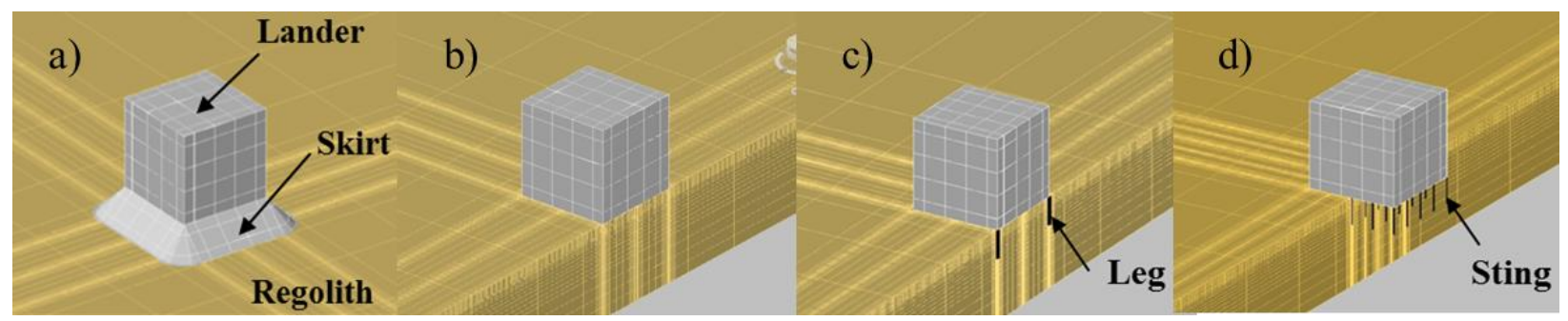

Figure 5. a) Skirt model, b) Ground touch model, c) Ground touch + Leg model, d) Ground touch + Sting model.

\section{B. Comparison}

The temperature fluctuations of the Skirt, Ground touch, Ground touch + leg, and Ground touch + Sting models were compared. The comparison of these primary proposed models is shown in Figure 6. In the figures and tables, the Skirt, Ground touch, Ground touch + leg, and Ground touch + Sting models are labeled Nos. 1, 2, 3, and 4, respectively. Conductances between the regolith and sting or lander were estimated at $10 \mathrm{~W} / \mathrm{m}^{2} \mathrm{~K}$. The conductance details are mentioned in a later section. Comparing the results, the model with most suppressed temperature fluctuations is No. 4. The reason for this analysis result is considered to be the heat exchange between the lander and regolith constant-temperature layer. This heat gets exchanged in No. 3 and increases in No. 4. The regolith constanttemperature layer works as a sink in the diurnal and as a heater in the night time. The temperature fluctuations of No. 4 differ by about $100^{\circ} \mathrm{C}$ compared to the non-active thermal control model. From this result, the efficiency of the Sting model is verified numerically. 


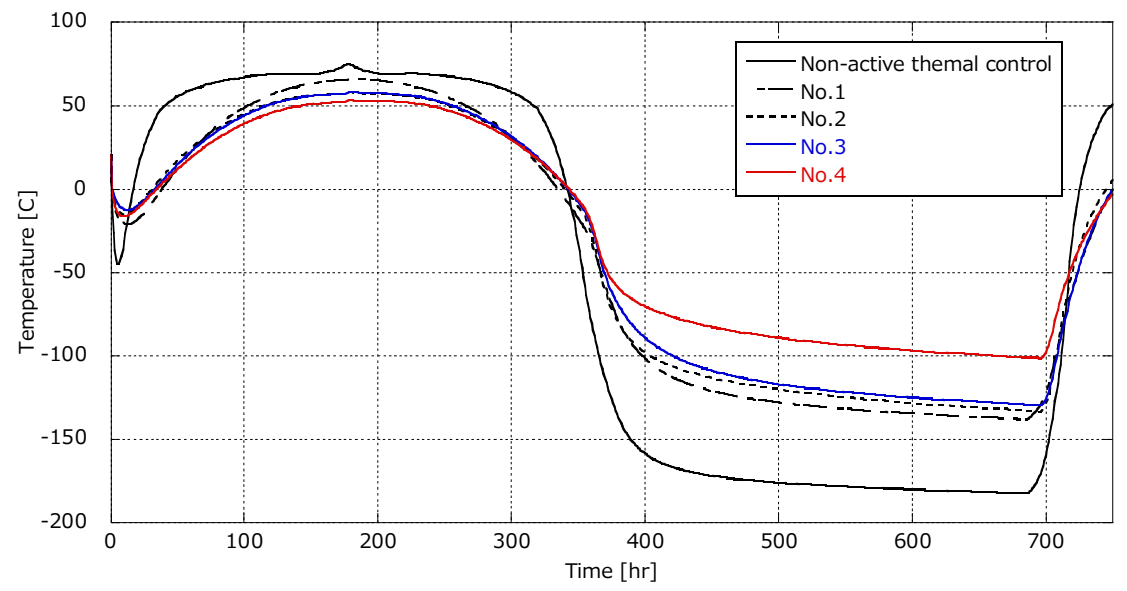

Figure 6. Comparison result of primary proposed models.

\section{Basic model}

The Basic model (sting model) is shown in Figure 7, whose effectiveness was proven in the previous section. This model has 25 stings below the cubic lander. The stings comprise aluminum alloy and are $\varnothing 5 \mathrm{~mm} \times 300 \mathrm{~mm}$ long. It is designed to reach the constant-temperature layer of lunar regolith, assumed to exist at a depth of $0.3 \mathrm{~m}$ below the surface. To optimize this model, a parametric study was performed. Two types of parameters were considered: shape and property. The shape parameters of the sting model are length, diameter, and the number of stings. The property parameters are thermal conductivity, thermal conductance, the effective emissivity of the multilayer insulation, and the regolith properties. In each analysis, the lander model temperature swings shown in the graphs are an average temperature of the cubic body of the lander.

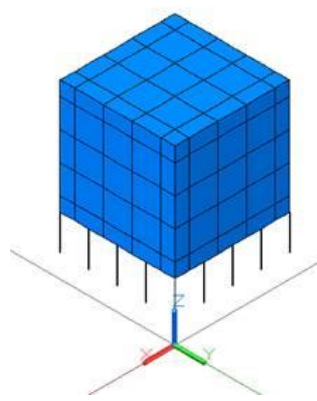

Table 4. Details of Basic model.

\begin{tabular}{c|c}
\hline Size & $1 \mathrm{~m} \times 1 \mathrm{~m} \times 1 \mathrm{~m}$ \\
\hline Material & Alminium honeycomb \\
\hline Insulation & $\begin{array}{c}\text { Multilayer insulation } \\
(10 \text { layers })\end{array}$ \\
\hline Inside & Black paint \\
\hline Internal heating & $0 \mathrm{~W}$ \\
\hline Sting material & Al6061 \\
\hline Sting size & $\emptyset 5 \mathrm{~mm} \times \mathrm{L} 30 \mathrm{~cm} \times 25$ \\
\hline
\end{tabular}

Figure 7. Basic model (sting model).

\section{Parametric study}

\section{Sting length}

The analysis was conducted with sting lengths of $30 \mathrm{~cm}, 50 \mathrm{~cm}$, and $75 \mathrm{~cm}$. Results of the model temperature swings versus sting lengths are shown in Figure 8 (a). As the stings get longer, the temperature range of the model lander decreases. An extension of 30-75 $\mathrm{cm}$ produced a temperature range of about $15^{\circ} \mathrm{C}$. However, we can see from the results that the ranges are likely to converge. From a manufacturing viewpoint, it must be easier to make shorter stings. Therefore, they should be designed to be as short as possible. 


\section{Number of stings}

The analysis was conducted with $25,45,81$, and 100 stings. Results of the model temperature versus the number of stings are shown in Figure 8 (b). As the number of stings increases, the temperature range of the model lander decreases, which indicates that as the number of stings increases from 81 to 100 , the effectiveness of each sting becomes insignificant compared to the others. This is believed to be related to the thermal diffusion length. The thermal diffusion length of lunar regolith is about $50 \mathrm{~mm}$, and the space between stings will become less than twice this distance as the number of stings increases from 81 to 100. From this finding, it can be estimated that the most effective spacing between stings is twice the thermal diffusion length.

\section{Sting diameter}

The analysis was conducted with sting diameters of 5, 50, 100, and $200 \mathrm{~mm}$. Figure 8 (c) shows the results of temperature swings versus sting diameter. The effect on temperature swings of the lander is quite significant compared to the other two shape parameters. In fact, as sting diameter increases, the temperature swing lessens. The temperature range difference between stings with diameters of $5 \mathrm{~mm}$ and $200 \mathrm{~mm}$ is about double. However, if sting diameters were designed larger, a loss of insertion ability into the regolith and an increase of mass could be expected.

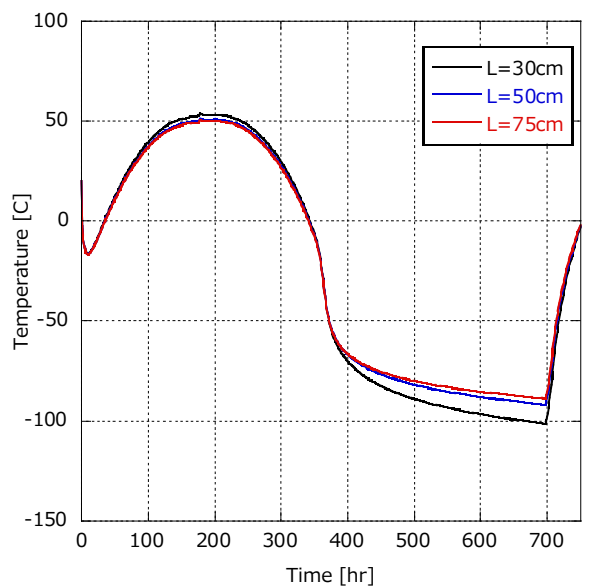

(a)

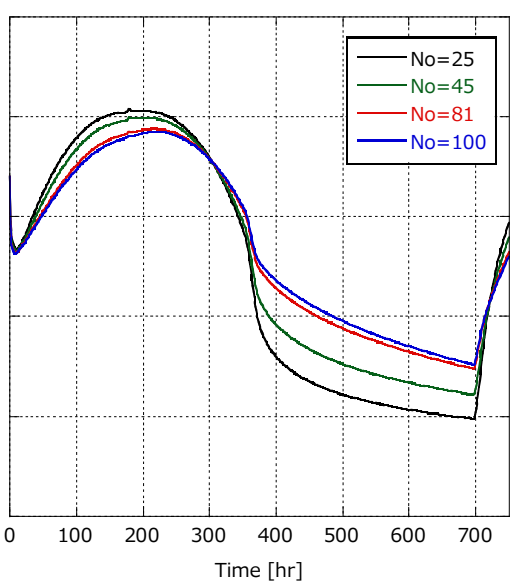

(b)

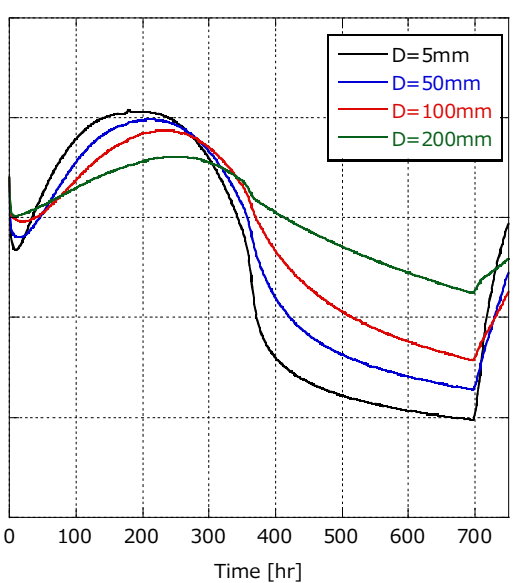

(c)

Figure 8. Temperature fluctuation of (a) length, (b) number of stings and (c) diameter.

\section{Thermal conductivity of sting}

Thermal conductivity depends on the material used. Analysis has been performed with conductivities with of 10 $\mathrm{W} / \mathrm{mK}, 167 \mathrm{~W} / \mathrm{mK}$, and $1000 \mathrm{~W} / \mathrm{mK}$. Figure 9 (a) shows the results of lander temperature versus the thermal conductivity of sting. The sting with a conductivity of $10 \mathrm{~W} / \mathrm{mK}$ has a different temperature fluctuation than the other two. However, there is a little difference between those two $(167 \mathrm{~W} / \mathrm{mK}$ and $1000 \mathrm{~W} / \mathrm{mK})$. As seen in the analysis results, high thermal conductivity does not change the temperature range significantly. Therefore, aluminum alloy $(167 \mathrm{~W} / \mathrm{mK})$ will be kept as the sting material for further models.

\section{Thermal conductance between sting and lander}

Analyses were conducted to see the effects of thermal conductance between a sting and the lander. Figure 9 (b) shows the results of lander and sting temperatures versus thermal conductance between the sting and lander. In Figure 9 (b), "cube" represents the cubic lander temperature and "sting" represents the average temperature of the attachment site of a sting with the bottom surface of the lander. At 1000 and $10000 \mathrm{~W} / \mathrm{m}^{2} \mathrm{~K}$, cubic lander temperature does not change from the infinite conductance result. Therefore, thermal conductance between sting and lander is an important parameter in designing the lander. The lander should be designed so that conductance is as high as possible. Originally, sting models were formed with zero resistance. This will continue to be used for further analysis. 


\section{Buried model}

A few centimeters beneath the surface, the lunar regolith has completely different temperature ranges. This model considers the compression made on the lunar regolith underneath the lander. Since regolith density depends on depth and is powdery near the surface, the regolith underneath the lander will decrease its volume due to the weight of the lander. In the analysis, $2 \mathrm{~cm}$ of compression of regolith is considered. This means that the bottom edge of the lander will be slightly covered with regolith. This is the same amount of compression as would be achieved by placing a load of $500 \mathrm{~kg} / \mathrm{m}^{2}$ on the regolith surface. The results in Figure 9 (c) show that even $2 \mathrm{~cm}$ of regolith covering the bottom edge affects the lander temperature swing.

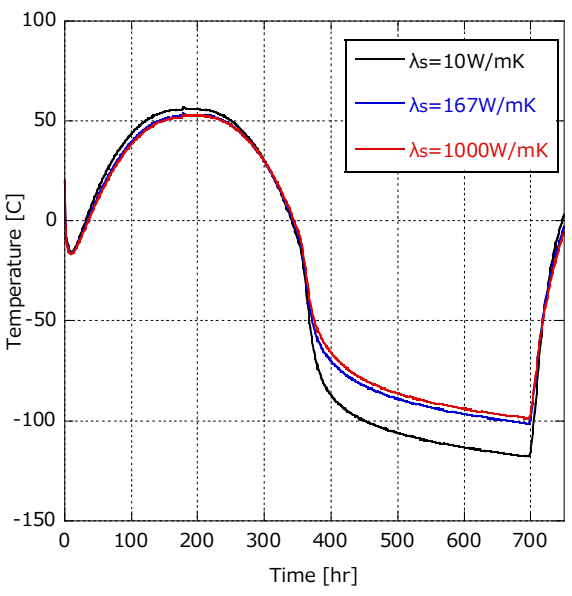

(a)

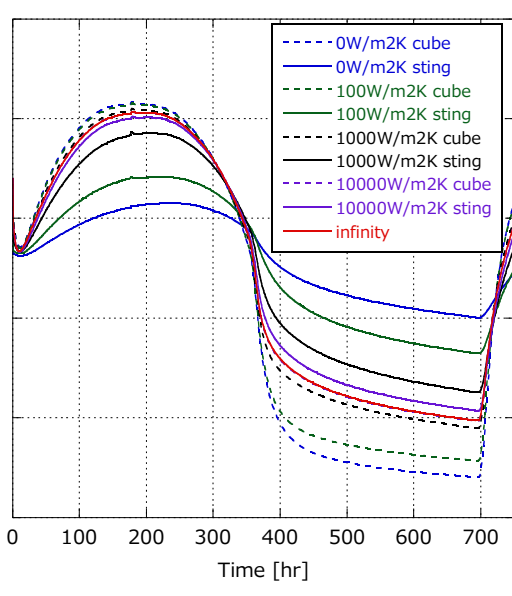

(b)

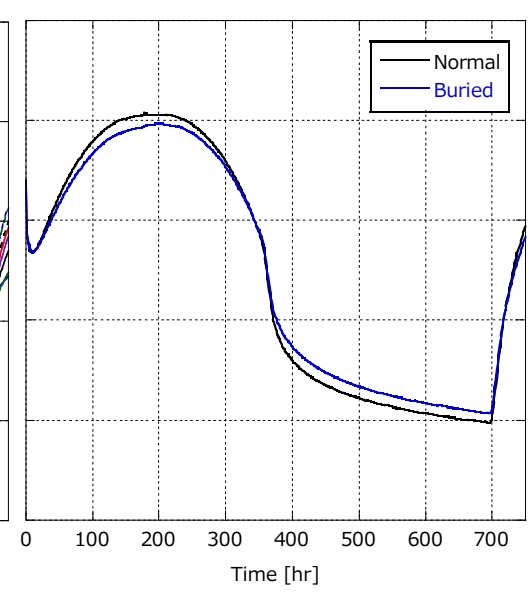

(c)

Figure 9. Temperature fluctuations for different (a) thermal conductivities of sting and (b) thermal conductances between the sting and the lander and (c) the Buried model.

\section{Thermal conductance between sting and regolith}

Thermal conductance between the sting, lander, and regolith is estimated using an equation developed from the Yovanovich theory. ${ }^{16}$ The estimation results are shown in Figure 10. To see the effects of conductance, the calculations were performed. Figure 11 shows the effects of varying the thermal conductance between the regolith and the lander and between the regolith and the stings. Figure 11 (a) shows the result of changing the conductance between the regolith and the lander for the Ground touch model. The results show that conductance has only a slight effect on lander temperature. This is because the effects of surrounding radiation are much greater than those of the contact conductance. Figure 11 (b) shows the results of the change of conductance between the regolith and the stings for the Basic model. If the conductance of the regolith and stings is $0 \mathrm{~W} / \mathrm{m}^{2} \mathrm{~K}$, the results would not be different from those of the Ground touch model. The results do not differ significantly with regolith and sting conductances of $10 \mathrm{~W} / \mathrm{m}^{2} \mathrm{~K}$ or $100 \mathrm{~W} / \mathrm{m}^{2} \mathrm{~K}$. Therefore, the conductance is estimated to be $10 \mathrm{~W} / \mathrm{m}^{2} \mathrm{~K}$ in the analysis.

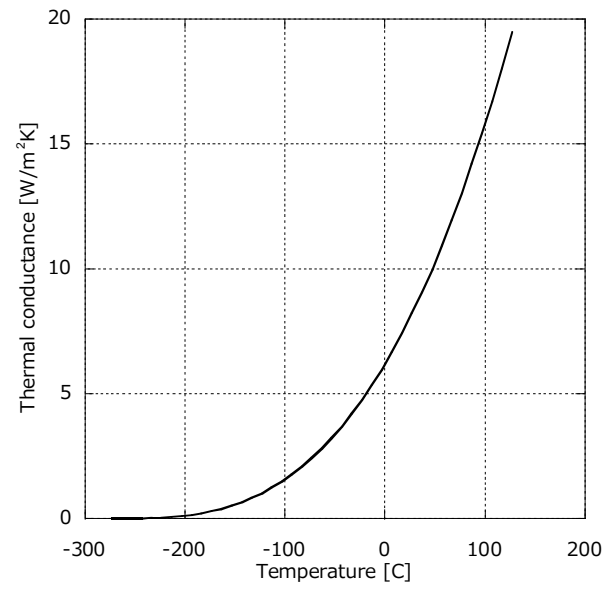

Figure 10. Estimation of thermal conductance between the sting, the lander, and the regolith. 


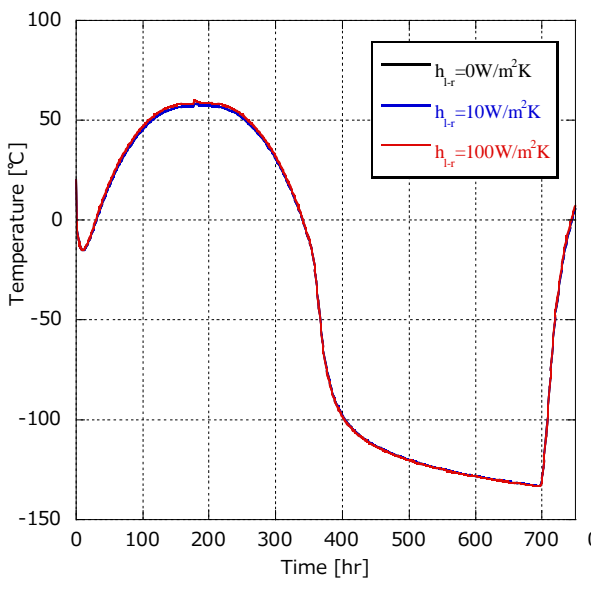

(a)

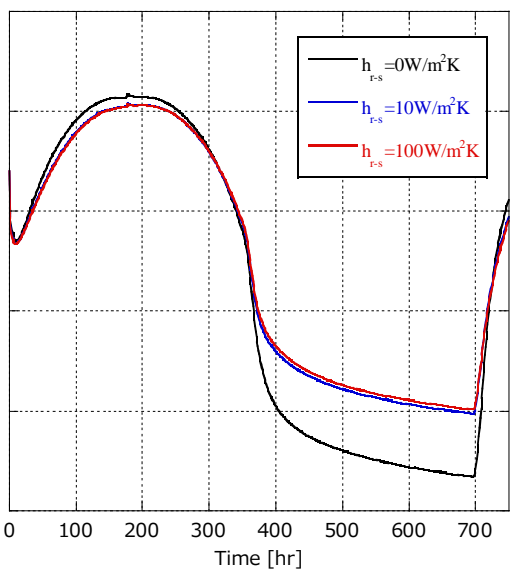

(b)

Figure 11. Temperature fluctuations for (a) the Ground touch model with different thermal conductances between the lander and the regolith, (b) the Sting model with different thermal conductances between the sting and the regolith.

\section{Lander panel material}

The lander panel material was changed to see the effects. The original material used was aluminum honeycomb. Aluminum alloys and copper were also analyzed. Figure 12 (a) shows the results of lander temperature swings with various lander panel materials. Aluminum alloy and copper further suppress the temperature fluctuations seen with aluminum honeycomb. This is predicted to be due to the effects of the specific heats and densities of the materials. Aluminum alloy and copper are denser compared to aluminum honeycomb. This leads to an increase in heat capacity. Considering the mass of material, aluminum honeycomb will still be used in the analysis. However, the selection of a material with high heat capacity has the potential to produce a better result.

\section{Multilayer insulation effective emissivity}

The effects of MLI effective emissivity were analyzed using the Ground touch model. Figure 12 (b) shows the analysis results of model temperature with various values of effective emissivity. Emissivity has a clear effect on the model lander temperature. Insulation effectiveness is greatest when emissivity is low. The analysis will be continued with an effective emissivity of 0.03 .

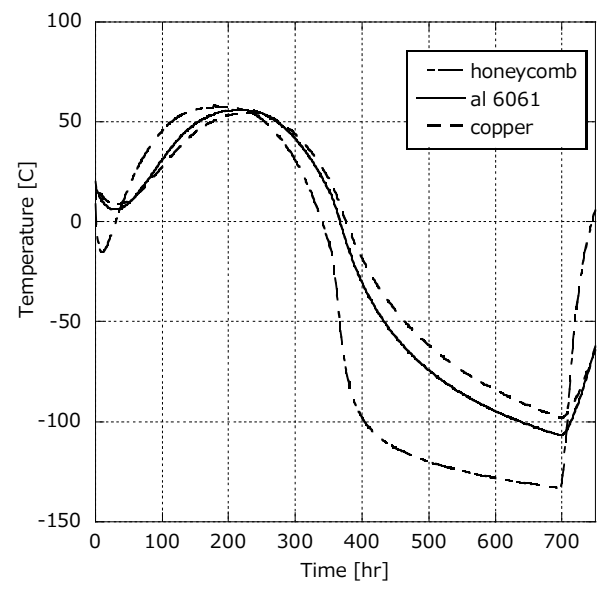

(a)

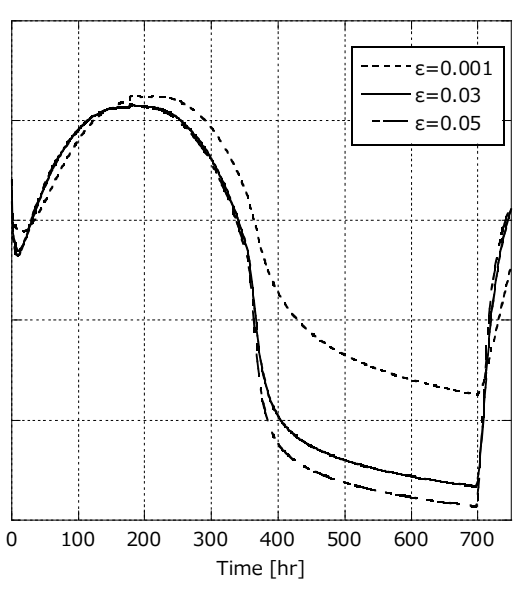

(b)

Figure 12. (a) Lander panel material effect and (b) MLI emissivity effects. 


\section{E. Candidate models}

From the results of the shape parametric studies, four new candidate models were created. These models suppressed their temperature swings by less than $60^{\circ} \mathrm{C}$. The temperature fluctuation results of the four models are shown in Figure 13. This temperature range for these models is about one-third of that for the Basic model. The only differences between the Basic model and these candidate models are the shape parameters and whether or not they are buried $2 \mathrm{~cm}$ in the regolith. Figure 14 shows schematic diagrams of the four models.

\section{a) Model No. 1}

This model increases the number of stings. The advantage of this model is that it has small diameter stings. Therefore, it is considered to be capable of successfully inserting stings into the regolith. Another advantage is the small sting volume; thus it is the lightest among the compared models. The disadvantages of this model are that 1) it must be carefully designed and operated because it is delicate and 2) its temperature swing is the largest of the four models.

\section{b) Model No. 2}

This model uses the largest diameter sting. Four extra stings are added. The advantage of this model is that it has few stings. The disadvantage is that it has a large sting volume, which leads to heaviness and difficulty in insertion.

\section{c) Model No. 3}

This is a model whose bottom surface is filled with 25 stings. Each sting has a diameter of $200 \mathrm{~mm}$ and a length of $50 \mathrm{~cm}$. The advantage of this model is that it has the smallest temperature range. The disadvantage is that this lander has a large quantity of aluminum attached to its underside.

\section{d) Model No. 4}

This model tries to optimize the number and diameter of stings. These two parameters conflict with each other. Therefore, this intermediate model was formed. It has 16 stings, each with a diameter of $175 \mathrm{~mm}$ and length of 75 $\mathrm{cm}$.

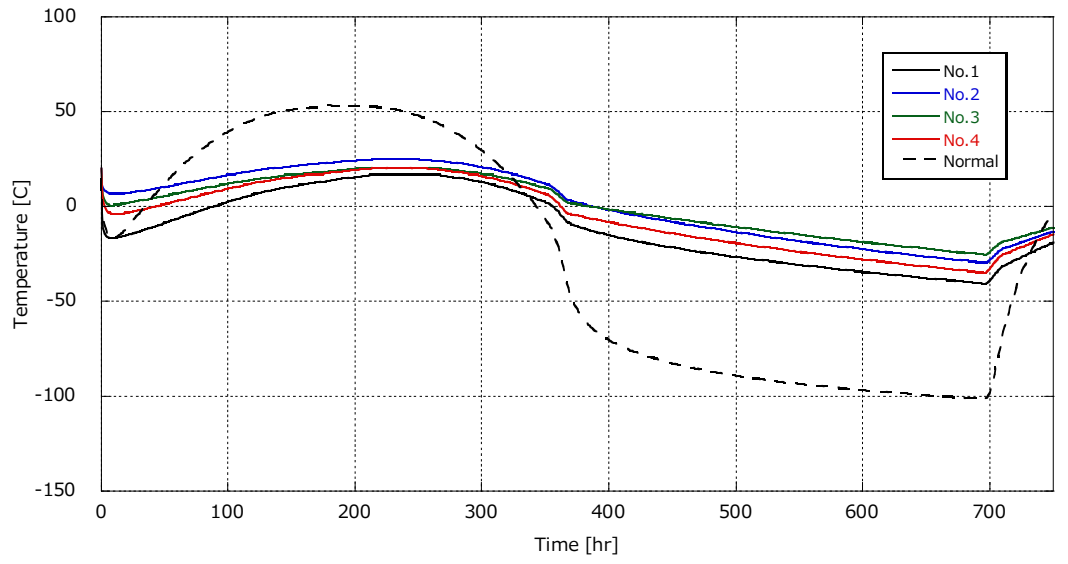

Figure 13. Temperature fluctuations of candidate models and Basic model.

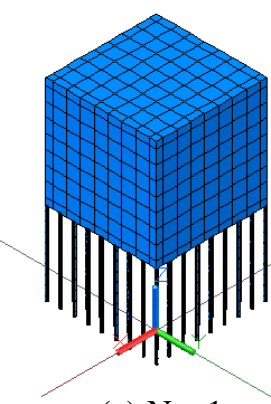

(a) No. 1

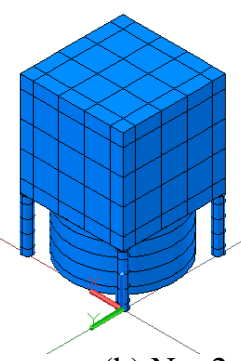

(b) No. 2

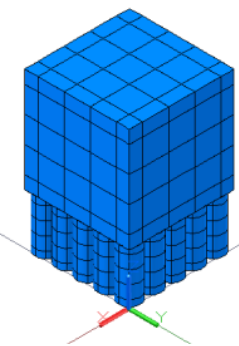

(c) No. 3

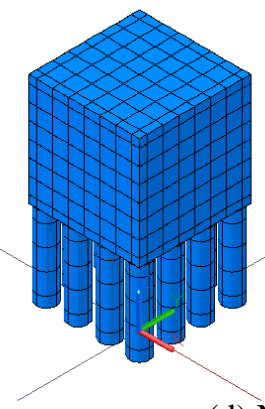

(d) No. 4

Figure 14. Candidate models. 


\section{F. New sting model}

Comparing the temperature swings of candidate models, model No. 1 was chosen as the new sting model. This is because where practicability is concerned, the shapes of the other three models are likely to be impossible to insert into the regolith. Therefore, the model with the thinnest stings became the new sting model. The next section describes the experimental verification of this model.

\section{Experiment}

In order to prove the effectiveness of the proposed method, a simulated lunar environment is required. However, it is difficult to completely simulate the lunar day/night thermal properties of regolith. Therefore, in a previous work of this study, a small-scale temporospatial experimental apparatus was fabricated. ${ }^{17}$

\section{A. Experimental apparatus}

Figure 15 shows a schematic view of the experimental apparatus. The apparatus consisted of a vacuum chamber, a shroud, regolith simulant, a simulant case, a vacuum exhaust unit, a cooling unit, a power source, a measurement unit, and a control unit. Toyoura standard sand plays the role of regolith simulant in this study. The thermal conductance between Toyoura standard sand and the lander was estimated to be similar to that of regolith and the lander as it was shown in the previous section (Figure 10). Also, measurement of thermal the environment was conducted, and was found to be similar to that of the lunar regolith. ${ }^{18}$ The measurement points of simulant are shown in Figure 16. Temperatures were controlled by a shroud, which was heated by a heater and cooled by liquid nitrogen. This provided the temperature swing for simulation of the lunar surface.

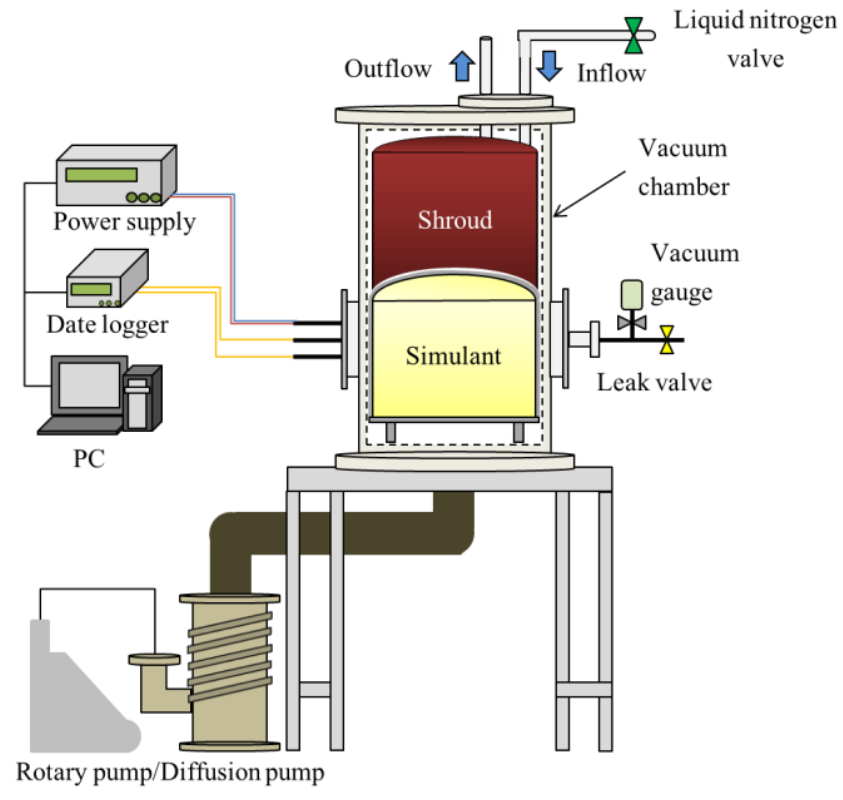

Figure 15. Schematic view of experimental apparatus

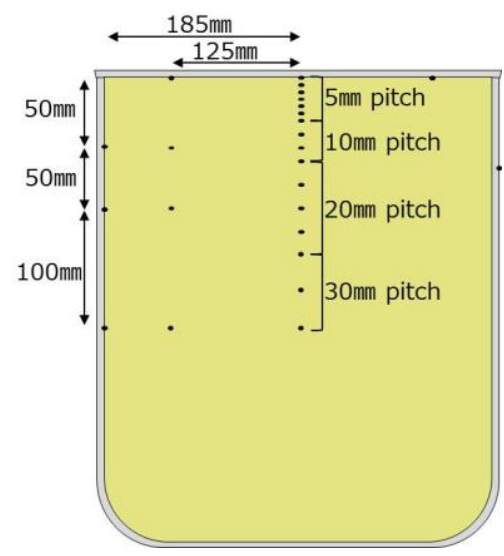

Figure 16. Measurement point of simulant.

\section{B. Cycle of experiment}

To determine the cycle period of the experiment, the method from Ref. 4 was used. Determining the experiment cycle requires the theory of thermal diffusion length, shown in Equation 1. Here $\alpha$ represents the thermal diffusivity and $f$ is the heat frequency, which is a reciprocal of the cycle period. Equation 2 shows the temperature equation for one-dimensional periodic heating. It shows the relation between the attenuation and phase lag of a heat source with amplitude $T_{0}$, where $x$ is the distance from the source and $t$ is the time. 


$$
\begin{gathered}
L_{t}=\sqrt{\frac{\lambda}{\pi \rho C_{p} f}}=\sqrt{\frac{\alpha}{\pi f}} \\
T(x, t)=T_{0} e^{-\frac{1}{L} x} \sin \left(\omega t-\frac{1}{L} x\right)
\end{gathered}
$$

$T_{0}$ is about $150^{\circ} \mathrm{C}$ in both the lunar environment and the experiment. From these two equations, the relation between the thermal diffusion length and the depth of the constant-temperature layer can be written as shown in Equation 3. Subscript $M$ represents the moon and $\mathrm{E}$ represents the experiment. At the constant-temperature layer, the temperature amplitude is less than $0.5^{\circ} \mathrm{C}$.

$$
\frac{L_{t M}}{L_{t E}}=\frac{d_{M}}{d_{E}}
$$

From these equations, the thermal diffusion length is set to one tenth that of the lunar environment by varying the heat frequency in the experiment. From the calculation, the cycle period was set to 10 hours. Table 5 shows the properties of both lunar regolith and regolith simulant (Toyoura standard sand).

Table 5. Properties of lunar regolith and experiment.

\begin{tabular}{c|c|c}
\hline Various factors & Lunar regolith & $\begin{array}{c}\text { Experiment } \\
\text { (Toyoura standard sand) }\end{array}$ \\
\hline$\rho\left(\mathrm{g} / \mathrm{cm}^{3}\right)$ & 1.71 & 2.63 \\
\hline$\lambda(\mathrm{W} / \mathrm{mK})$ & $0.001 \sim$ & 0.005 \\
\hline$C_{p}(\mathrm{~J} / \mathrm{kgK})$ & 666 & 715 \\
\hline Thermal diffusion length $(\mathrm{mm})$ & 58 & 5.8 \\
\hline Constant temperature layer $(\mathrm{mm})$ & 347 & 34.7 \\
\hline Cycle period $(\mathrm{hr})$ & 709 & 10 \\
\hline
\end{tabular}

\section{Model lander construction}

The model lander for the experiment was set to one-tenth scale of the lunar model in order to match the cycle period. There were three models named the Ground touch model, New sting model and Lander model. Figure 17 shows these models, and Table 6 shows the correspondence of the experimental model to the lunar scale analysis model. The Ground touch model was only the cubic lander model with its bottom in contact with the regolith surface. The New sting model was the candidate model selected from the lunar thermal analysis. It had 81 stings of $\varnothing 2 \mathrm{~mm} \times$ $75 \mathrm{~mm}$ made of SUS 304 stainless steel mounted underneath the cubic lander. SUS 304 was used as the sting material because it has one-tenth the thermal conductivity of aluminum alloy. This was also matched to the cycle period. The lander model was the cubic lander with four $\varnothing 1 \mathrm{~cm} \times 3 \mathrm{~cm}$ legs under each corner. The legs prevented the cubic lander raised above the simulant surface. The insides of all panels and the outside of the bottom panel were painted with black paint (Aeroglaze Z306). The stings were also painted. Panels were glued with aluminum tape, and the cubic lander was covered with 20 layers of MLI. Stings were inserted into holes made in the bottom panel. Temperature was measured by an average of 7 thermocouples on the model lander: four inside the panels and three outside the panels (underneath the MLI). Two thermocouples were on the top panel, two were on the side panels, and one was on the bottom panel. 


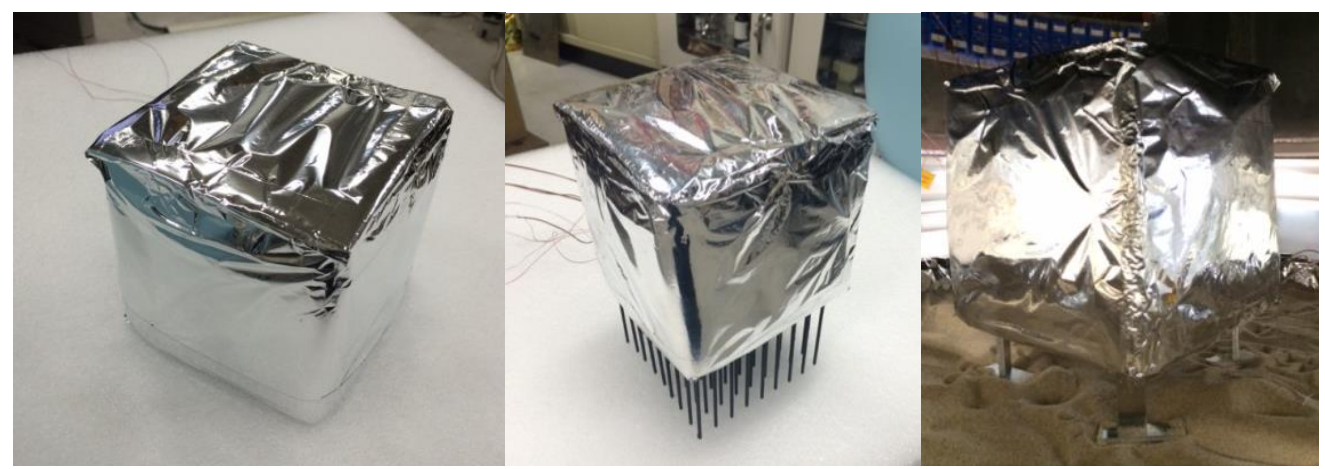

Figure 17. Ground touch model (left), New sting model (middle), Lander model (right).

Table 6. Correspondence of experimental model to lunar scale analysis model. *Changed point

\begin{tabular}{c|c|c}
\hline & Lunar surface scale & Experiment \\
\hline \multirow{3}{*}{ Cubic lander } & $1 \times 1 \times 1 \mathrm{~m}^{3}$ & $100 \times 100 \times 100 \mathrm{~mm}^{3}$ \\
& 1-cm-thick aluminium honeycomb & $* 1$-mm-thick aluminium alloy \\
Black paint (inside, bottom) & $* 20$-layer multilayer insulation \\
\hline \multirow{5}{*}{ Sting } & 10-layer multilayer insulation & $*$ SUS304 $(16.7 \mathrm{~W} / \mathrm{mK})$ \\
& Aluminium alloy $(167 \mathrm{~W} / \mathrm{mK})$ & $\varnothing 2 \mathrm{~mm} \times 75 \mathrm{~mm} \times 81$ \\
& $\varnothing 20 \mathrm{~mm} \times 750 \mathrm{~mm} \times 81$ & Black paint $(\varepsilon=0.82)$ \\
\hline
\end{tabular}

\section{Results}

Figure 18 shows the simulated lunar experiment results. The black line represents the shroud set point temperature, and the brown line represents the regolith simulant surface temperature. The blue, red, and green lines represent the Ground touch model, New sting model, and Lander model, respectively. The abovementioned model temperatures are the average of 7 measurement points. Comparing the model lander temperatures, New sting model had the smallest temperature fluctuation. On the other hand, the Lander model had the largest fluctuation among the models. The temperature range of the New sting model was one-tenth compared to that of the Lander model and half the range of the Ground touch model. This proved the effectiveness of New sting model empirically. The temperature fluctuation range difference between the Ground touch model and New sting model is not as remarkable as compared with the Lander model. However, the analysis results of the lunar-scale models (Figure 19) show that although the difference between the Ground touch model and New sting model is not significant on the experiment scale, the difference between the two models is remarkable on the lunar scale. The temperature range difference between these two models is up to $130^{\circ} \mathrm{C}$.

An experimental analysis model was developed for each model. Overall temperature swings are the same between the experiment and analysis. The largest temperature difference between the experiment and analysis is $20 \%$ at the second period maximum temperature of the Ground touch model. The average temperature differences of all models are less than $11 \%$. The difference between the experiment and analysis tends to get larger as the models interact with the regolith simulant. Moreover, time lags at maximum and minimum temperatures appear in the Ground touch model and New sting model. This also tends to become larger as heat exchange with a simulant is encouraged. In the case of the Lander model, the time lag is only $2 \mathrm{~min}$ on average. This corresponds to $0.3 \%$ of its cycle period, which can be ignored as zero. On the other hand, the average time lag of the New sting model is 20 times that of the Lander model. This corresponds to $7.8 \%$ of its cycle period. Therefore, the reason for the difference is believed to be related to the properties of the regolith simulant used in analysis. To make a more accurate analysis model of the experiment apparatus, reconsideration of the properties of regolith simulant may be required. 


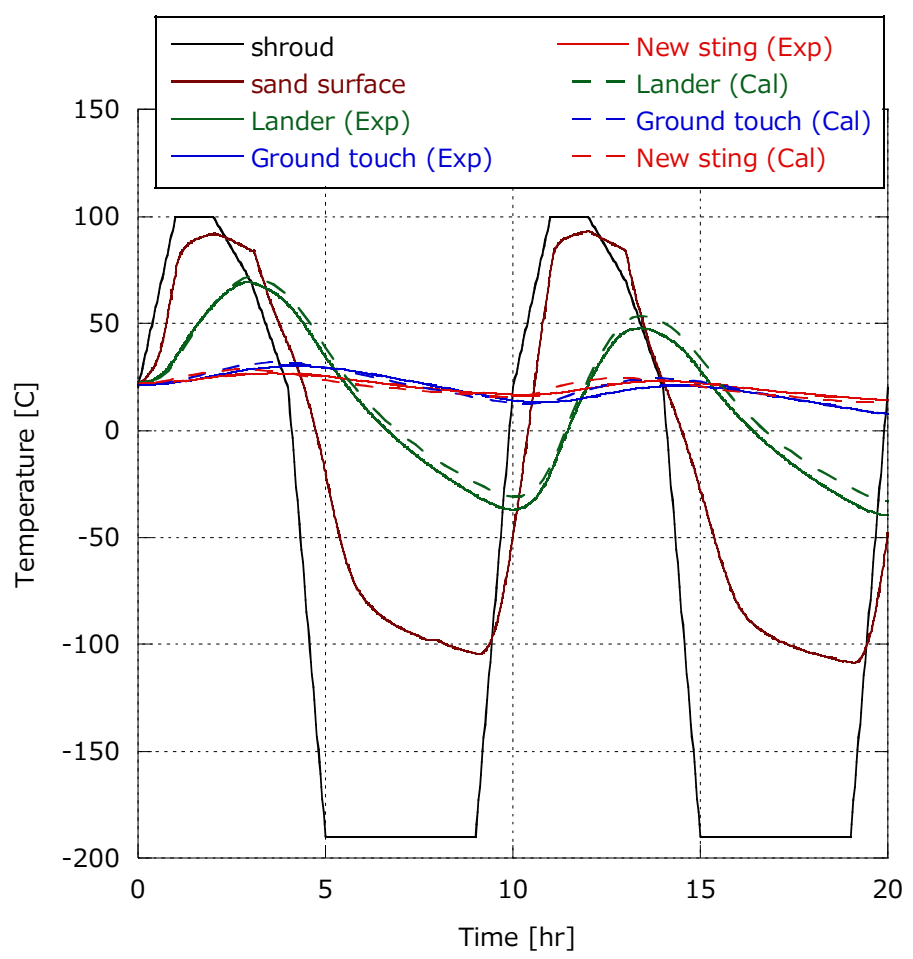

Figure 18. Experiment result

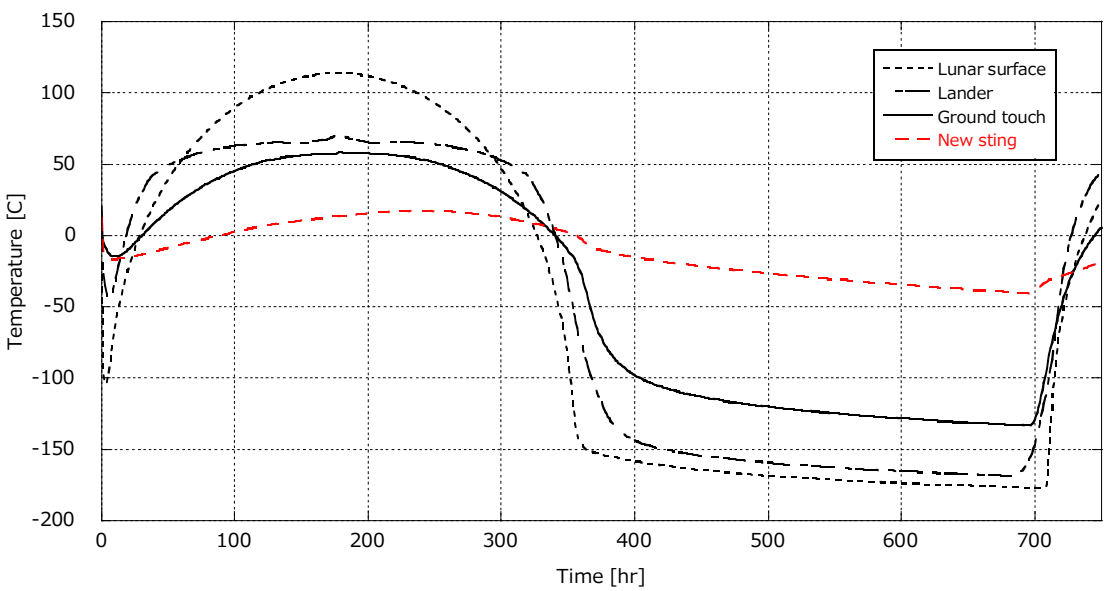

Figure 19. Model analysis result in lunar scale.

\section{Conclusion}

The purpose of this study was to make a completely passive thermal control design for a lunar surface lander faced with large temperature swings. In order to make the proposed model, some parametric thermal analyses and experiments were conducted. Through parametric study analyses, the efficacy of a New sting model was verified. This model utilized aluminum rods in contact with the constant-temperature layer of the regolith, which lies at $0.3 \mathrm{~m}$ beneath the lunar surface. Then, through an experiment involving the Lander model, Ground touch model, and New sting model, the efficacy of the New sting model was proven empirically. These analytical and experimental results indicate the possibility of completely passive thermal control on the lunar surface. Moreover, it shows that MLI has a relatively large effect on the performance of thermal control. Therefore, the improvement of the effective emissivity of MLI may contribute massively in decreasing the temperature differences of lunar landers.

However, this still depends greatly on the actual design details and means of coupling. Therefore, one of the next conceivable steps of the lunar analysis model is to put instruments inside the lander. Taking the internal heat of 
operating instruments into consideration will lead to an advanced model that is closer to real lander conditions. Also, the shape of the proposed model is good for the thermal problem of the lunar surface, but it creates a potential difficulty for mechanical insertion into the lunar regolith. Therefore, these points may become the subjects of future research.

\section{References}

${ }^{1}$ Heiken, G. H., Vaniman, D. T., and French, M., "Lunar Sourcebook:A user's guide to the moon", Cambridge University Press, 1991.

${ }^{2}$ Hager, P. B., "Characterizing transient thermal interactions between lunar regolith and surface spacecraft," Planetary and Space Science, Vol.92, pp101-116, 2014.

${ }^{3}$ Balasubramaniam, R., Wegeng, R. S., Gokoglu, S. A., Suzuki, N. H., and Sacksteder, K. R., "Analysis of Solar-Heated Thermal Wadis to Support Extended-Duration Lunar Exploration," NASA/TM-2010-216254, 2010.

${ }^{4}$ Notsu, R., Nagano, H., and Ogawa, H., "Conceptual Verification of Lunar Long-Duration Method by Using High-HeatStorage-Capability of Regolith," Journal of Thermophysics and Heat Transfer, Vol.29, No.1, pp.65-73, 2014.

${ }^{5}$ Houston, W.N., Mitchell, J.K., and Carrier, W.D., "Lunar soil and porosity," Proceedings of the Fifth Lunar Science Conference, Vol.3, pp2361-2364, 1974.

${ }^{6}$ Horai, K., and Fujii, N., "Thermophysical Properties of Lunar Material Returned by Apollo Missions," Proceeding of the Conference on Lunar Geophysics, pp447-475, 1971.

${ }^{7}$ Langseth, M.G., Keihm, S.J., and Peters, K., "Revised lunar heat-flow values," Proceedings of the Seventh Lunar Science Conference, pp3143-3171, 1976.

${ }^{8}$ Grott, M., Knollenberg, J., and Krause, C., "Apollo lunar heat flow experiment revisited: A critical reassessment of the in situ thermal conductivity determination," Journal of Geophysical Research, Vol.115, E11005, 2010.

${ }^{9}$ Cremers, C. J., and Hsia, H.S., "Thermal conductivity and diffusivity of Apollo 15 fines at low density," Proceedings of the Fourth Lunar Science Conference, Vol.3, pp2459-2464, 1973.

${ }^{10}$ Cremers, C. J., "Thermophysical Properties of Apollo 14 Fines,” Journal of Geophysical Research, Vol.80, No.32, 1975.

${ }^{11}$ Cremers, C. J., "Thermophysical properties of Apollo 12 fines," Icarus, Vol.18, pp294-303, 1973.

${ }^{12}$ Vasavada, A., Bandfield, J., Greenhagen, B., Hayne, P. O., Siegler, M. A., Williams, J., and Paige. D. A., "Lunar equatorial surface temperatures and regolith properties from the Diviner Lunar Radiometer Experiment," J Geophys Res-Planet, Vol.117, E00H18, 2012

${ }^{13}$ Cremers, C. J., "Lunar surface temperatures from Apollo 12," ICARUS Vol.18,294-303, 1973.

${ }^{14}$ Cremers, C. J., "Thermal conductivity of Apollo 16 lunar fines," Proceeding of the Fifth Lunar Conference, Vol.3, pp.2703-2708, 1974.

${ }^{15}$ Ogawa, K., Iijima. Y., Sakatani. N., Otake. H., and Tanaka. S., "A thermal control system for long-term survival of scientific instruments on lunar surface.", The Review of scientific instruments, Vol.85, 035108, 2014.

${ }^{16}$ Kömle, N., Hütter, E., Kargl, G., "Development of Thermal Sensors and Drilling Systems for Application on Lunar Lander Missions", Earth, Moon, and Planets, Vol.103, 3-4, pp119-141, 2008.

${ }^{17}$ Notsu, R., Nagano, H., and Ogawa, H., "A proposal of lunar long duration method (Fabrication of lunar environment simulator and experimental validation)," JSME, Vol.80, No.815, 2014.

${ }^{18}$ Okazaki, H., and Nagano, H., "Development of Lunar Thermal Environment Model and Equipment for Lunar LongDuration-Mission," Proceeding of the $48^{\text {th }}$ JSASS, A-13, 2011. 